Article

\title{
Comparative Physiological Analysis of Methyl Jasmonate in the Delay of Postharvest Physiological Deterioration and Cell Oxidative Damage in Cassava
}

\author{
Guoyin Liu ${ }^{1,2}$, Bing Li ${ }^{1}$, Xiuqiong Li ${ }^{1}$, Yunxie Wei ${ }^{1, *}$, Debing Liu ${ }^{3, *}$ and Haitao Shi ${ }^{1, *}$ \\ 1 Hainan Key Laboratory for Sustainable Utilization of Tropical Bioresources, College of Tropical Crops, \\ Hainan University, Haikou 570228, China \\ 2 College of Forestry, Hainan University, Haikou 570228, China \\ 3 College of Applied Science and Technology, Hainan University, Danzhou 571737, China \\ * Correspondence: weiyunxie1989@126.com (Y.W.); ldebing@126.com (D.L.); haitaoshi@hainanu.edu.cn (H.S.); \\ Tel.: +86-898-66160721 (Y.W.); +86-898-23300600 (D.L.); +86-898-66160721(H.S.)
}

Received: 19 August 2019; Accepted: 2 September 2019; Published: 5 September 2019

\begin{abstract}
The short postharvest life of cassava is mainly due to its rapid postharvest physiological deterioration (PPD) and cell oxidative damage, however, how to effectively control this remains elusive. In this study, South China 5 cassava slices were sprayed with water and methyl jasmonate (MeJA) to study the effects of MeJA on reactive oxygen species, antioxidant enzymes, quality, endogenous hormone levels, and melatonin biosynthesis genes. We found that exogenous MeJA could delay the deterioration rate for at least $36 \mathrm{~h}$ and alleviate cell oxidative damage through activation of superoxide dismutase, catalase, and peroxidase. Moreover, MeJA increased the concentrations of melatonin and gibberellin during PPD, which had a significant effect on regulating PPD. Notably, exogenous MeJA had a significant effect on maintaining cassava quality, as evidenced by increased ascorbic acid content and carotenoid content. Taken together, MeJA treatment is an effective and promising way to maintain a long postharvest life, alleviate cell oxidative damage, and regulate storage quality in cassava.
\end{abstract}

Keywords: cassava; methyl jasmonate; postharvest physiological deterioration; cell oxidative damage; reactive oxygen species

\section{Introduction}

Cassava (Manihot esculenta) is one of the most important tropical crops [1,2]. Due to the short postharvest shelf-life of cassava, its potential market benefit to cassava farmers is severely restricted. Postharvest physiological deterioration (PPD) is harmful during harvesting and safekeeping, and the burst of reactive oxygen species (ROS) results in serious cell oxidative damage [2-5]. ROS is regulated by an antioxidant system including enzymatic and non-enzymatic scavenging mechanisms [6]. The enzymatic scavenging mechanism mainly consists of catalase (CAT), superoxide dismutase (SOD), ascorbate peroxidase (APX), and peroxidase (POD), while the non-enzymatic scavenging mechanism includes reduced forms of ascorbate, carotenoids, and flavonoids [7].

So far, various treatments have paid more attention to inhibiting cassava PPD. For example, hot water treatment for $10 \mathrm{~min}$ and modified atmosphere packaging have significant effects on delaying PPD during cassava postharvest storage [8]. In addition, keeping the cassava at $10{ }^{\circ} \mathrm{C}$ and $80 \%$ relative humidity could also delay PPD for $14 \mathrm{~d}$ [9]. Meanwhile, exogenous treatments with some small molecules, such as melatonin [10-12] and $\mathrm{CaCl}_{2}$ [12], can delay the postharvest shelf-life of cassava root. Although traditional or genetic breeding methods can inhibit PPD in cassava $[13,14]$, these methods still have many problems such as long-term breeding, biosafety, and others [1]. Generally, all the above 
methods have both advantages and shortcomings. Therefore, other suitable techniques for delaying or inhibiting PPD in cassava need to be further investigated.

As an important plant growth regulator, methyl jasmonate (MeJA) has significant effects on quality $[15,16]$, fruit ripening, senescence, and underlying parameters $[17,18]$. Previous studies have demonstrated that MeJA treatment can induce the expression levels of SOD, POD, and CAT $[17,18]$ to decrease the levels of hydrogen peroxide $\left(\mathrm{H}_{2} \mathrm{O}_{2}\right)$ and superoxide anion $\left(\mathrm{O}_{2}{ }^{-}\right)$[19], thereby improving stress resistance [17]. MeJA treatment is also conducive to the maintenance of eggplant quality during storage, inhibiting the weight loss and calyx browning [18]. Postharvest treatment with MeJA maintains higher concentrations of sugars and organic acids in fresh kiwifruit [20] and mangoes [21]. Moreover, the application of MeJA to fruits and vegetables can increase the accumulation of flavonoids [22-24] and quality [25-27]. Additionally, soluble solids can also be significantly induced by MeJA treatment [28].

Although MeJA has significant effects on fruit ripening and storage quality, the direct correlation between MeJA and PPD in cassava remains unclear. In this study, comparative physiological analysis was performed to reveal the effect of MeJA in PPD, cell oxidative damage, and cassava quality. Notably, the relationship between MeJA and melatonin during cassava PPD was also revealed.

\section{Materials and Methods}

\subsection{Plant Materials and Treatments}

Manihot esculenta Crantz. cv. Mainland South China 5 (SC5) cassava roots were harvested from nine-month-old cassava in Baisha County, Hainan Province, China. The cassava roots were washed with double distilled water, the proximal and distal parts of the cassava roots were eliminated, and the remaining roots were cut to $5-10 \mathrm{~mm}$ thick cassava slices. The cassava slices were randomly divided into nine treatments and each treatment included 45 cassava slices. Cassava slices were sprayed with either mock (the control having the same $\mathrm{pH}$ as the other treatments), $20 \mu \mathrm{M}$ MeJA, $0.5 \mathrm{mM}$ MeJA, $5 \mathrm{mM}$ MeJA, $10 \mathrm{mM}$ MeJA, $20 \mu \mathrm{M}$ gibberellin (GA), $2.5 \mathrm{mM} \mathrm{GA}, 5 \mathrm{mM} \mathrm{GA}$, or $10 \mathrm{mM}$ GA as different treatments, and kept at $25^{\circ} \mathrm{C}$ with $60 \%-75 \%$ relative humidity. The cassava root slices were gathered at $0,12,24$, and $48 \mathrm{~h}$, then frozen in liquid nitrogen and stored at $-80{ }^{\circ} \mathrm{C}$ for subsequent determination. For the reagents, MeJA (39924-52-2, purity $\geq 95 \%$, Solarbio, Beijing, China) and GA (77-06-5, purity $\geq 90 \%$, Biotopped, Beijing, China) were used.

\subsection{Visual PPD Evaluation}

Visual inspection of each slice was conducted at $0,12,24,36,48$ and $72 \mathrm{~h}$. The vascular discoloration was quantified as determined percentages using ImageJ analysis software (http://rsb.info.nih.gov/ij/). The percentages of gray values indicate the deterioration rate at each time point by the software. The gray value at $0 \mathrm{~h}$ was set to 1 .

\subsection{Assays of ROS Accumulation and Antioxidant Enzyme Activities}

The endogenous ROS accumulation and antioxidant enzyme activities were determined with a microplate reader. Briefly, $0.5 \mathrm{~g}$ of root slices were taken and mixed with $5 \mathrm{~mL}$ with a $50 \mu \mathrm{M}$ phosphate buffer ( $\mathrm{pH} 7.8$ ). After centrifuged at $12,000 \times \mathrm{g}$ for $10 \mathrm{~min}$ at $4{ }^{\circ} \mathrm{C}$, the supernatant was collected for determination of $\mathrm{H}_{2} \mathrm{O}_{2}$ and $\mathrm{O}_{2}{ }^{-}$content as well as enzyme activities. The content of $\mathrm{O}_{2}{ }^{-}$was determined according to the hydroxylamine reaction method. The content of $\mathrm{H}_{2} \mathrm{O}_{2}$ and activities of CAT, POD, and SOD were detected using the $\mathrm{H}_{2} \mathrm{O}_{2}$ Assay Kit (A064, Jiancheng, Nanjing, China), CAT Assay Kit (A007-1, Jiancheng, Nanjing, China), POD Assay Kit (A084-3, Jiancheng, Nanjing, China), and SOD Assay Kit (A001-4, Jiancheng, Nanjing, China), respectively, according to the manufacturer's guidelines. 


\subsection{RNA Isolation and Quantitative Real-Time PCR ( $q R T-P C R$ )}

Total RNA isolation and qRT-PCR was performed according to the manufacturer's guidelines as described by Wei et al. [29]. The protocol of qRT-PCR included $95^{\circ} \mathrm{C}$ for $10 \mathrm{~min}$, followed by 45 cycles of $95^{\circ} \mathrm{C}$ for $30 \mathrm{~s}, 55^{\circ} \mathrm{C}$ for $30 \mathrm{~s}$, and $72{ }^{\circ} \mathrm{C}$ for $30 \mathrm{~s}$. Then the relative transcription levels were evaluated using the comparative $2^{-\triangle \Delta C T}$ method with MeEF1 as the reference gene. The primers have been previously described [30].

\subsection{Determination of Endogenous Melatonin and GA}

The endogenous melatonin and GA were quantified using the Melatonin Enzyme-Linked Immunosorbent Assay (ELISA) Kit (HLE97243, Haling Biotechnology, Shanghai, China) and GA ELISA Kit (HLE97151, Haling Biotechnology, Shanghai, China) respectively, according to the manufacturer's protocols.

\subsection{Quantification of Starch, Soluble Sugar, Ascorbic Acid, and Carotenoid}

The level of ascorbic acid was determined using the Ascorbic Acid Assay Kit (A009, Jiancheng, Nanjing, China). The concentrations of soluble sugar and carotenoid were measured as described by Gao [31]. Briefly, the homogenate was extracted twice in $5 \mathrm{~mL}$ of $80 \%$ ethanol at $80{ }^{\circ} \mathrm{C}$ for $30 \mathrm{~min}$. After centrifugation at $12,000 \times g$ for $10 \mathrm{~min}$ at room temperature, the supernatant was collected for the determination of soluble sugar by an anthrone colorimeter. Carotenoid was extracted from $0.5 \mathrm{~g}$ of cassava root slices using $5 \mathrm{~mL}$ of $96 \%$ ethanol, and the absorbance was determined at 665,649 , and $470 \mathrm{~nm}$, using a microplate reader and a 96-well plate. Meanwhile, starch concentration was determined as described by Cao et al. [32]. For starch determination, the homogenate was extracted twice in $5 \mathrm{~mL}$ of $80 \%$ ethanol at $80^{\circ} \mathrm{C}$ for $30 \mathrm{~min}$, residuals were gelatinized at $100{ }^{\circ} \mathrm{C}$ for $15 \mathrm{~min}$, then $2 \mathrm{~mL}$ of $9.2 \mathrm{~mol} / \mathrm{L}$ perchloric acid was added for further extraction for $15 \mathrm{~min}$. After being centrifuged at $12,000 \times g$ for $10 \mathrm{~min}$ at room temperature, the supernatant was collected for the determination of starch.

\subsection{Statistical Analysis}

All experiments were performed with at least three independent biological replicates. All data were shown as means $\pm \mathrm{SD}$, and were analyzed using ANOVA and SAS 9.1.3 statistics software (9.1.3, SAS Instituteinc, North Carolina, NC, USA) for Duncan's multiple range test. Asterisk symbols $\left(^{*}\right)$ indicated a significant difference at $p<0.05$ at the same time.

\section{Results}

\subsection{The Effect of MeJA Treatment on PPD}

As shown in Figure 1A, the effect of MeJA on postharvest physiological deterioration (PPD) symptoms of cassava storage roots was revealed. In addition, the deterioration rate is shown in Figure 1B. Obviously, higher concentration of MeJA ( $5 \mathrm{mM}$ and $10 \mathrm{mM})$ significantly delayed the development of PPD and decreased deterioration rate (Figure 1). Thus, $10 \mathrm{mM}$ MeJA was selected for further study. 

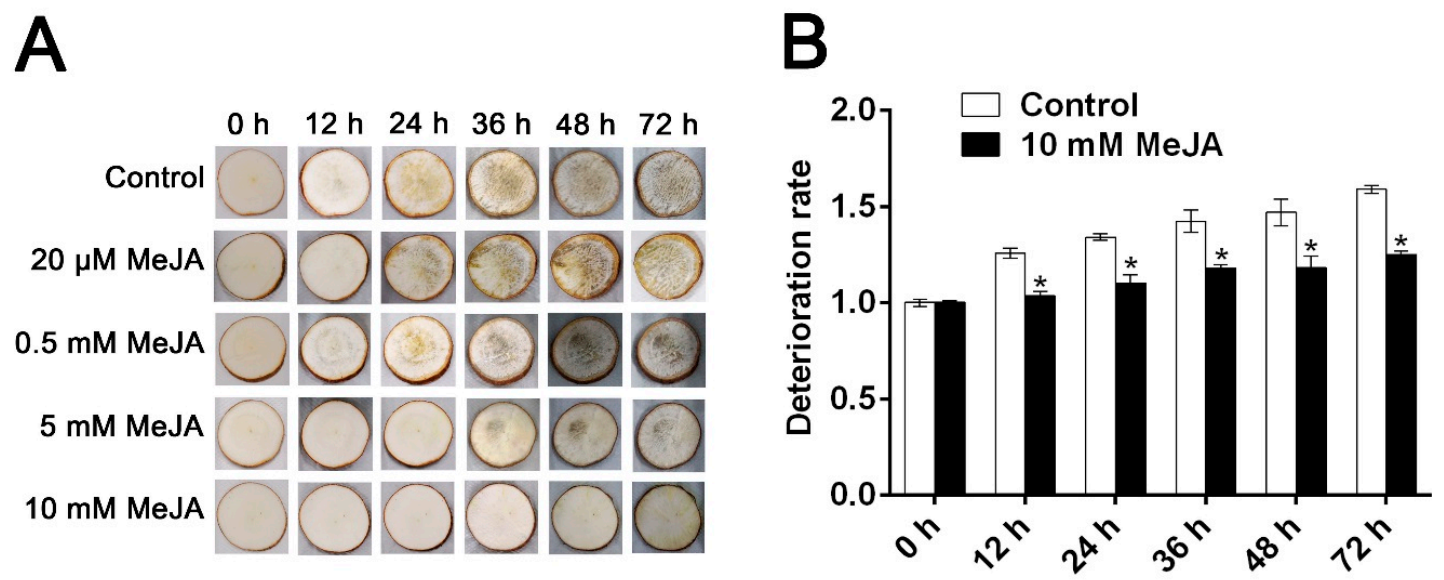

Figure 1. The effects of methyl jasmonate (MeJA) on postharvest physiological deterioration (PPD) in cassava storage root slices of South China 5 (SC5) variety. Visual detection (A) and deterioration rate (B) of storage root slices during PPD. Deterioration rate was determined by the percentages of gray values at different time points. Data are means \pm SD calculated from at least three biological replicate samples. Asterisk symbols $\left(^{*}\right)$ indicate significant differences according to Duncan's multiple range test at $p<0.05$ at the same time points.

After $12 \mathrm{~h}$ of water treatment, a brown color symptom was observed in the cassava root slices. However, the symptom in question did not manifest until $72 \mathrm{~h}$ with $10 \mathrm{mM}$ MeJA treatment (Figure $1 \mathrm{~A}$ ). On the contrary, the untreated cassava root slices displayed a high deterioration rate (Figure 1B). The results obviously showed that the deterioration rate of root slices was gradually increased during storage time, and $10 \mathrm{mM}$ MeJA delayed early development of PPD in root slices (Figure 1). These results indicated that exogenous application of MeJA could delay the occurrence of PPD in cassava root slices.

\subsection{MeJA Alleviates Cell Oxidative Damage through Modulation of ROS and Underlying Antioxidant Enzymes}

To explore whether MeJA-induced delay of PPD was related to ROS scavenging in cassava root slices during the storage period, the concentrations of $\mathrm{H}_{2} \mathrm{O}_{2}$ and $\mathrm{O}_{2}{ }^{-}$were determined at different time points (Figure 2). Moreover, the concentrations of $\mathrm{H}_{2} \mathrm{O}_{2}$ and $\mathrm{O}_{2}{ }^{-}$in MeJA-treated cassava were significantly lower than that of untreated cassava at $24 \mathrm{~h}$, while there was no significant difference at other time points. Antioxidant enzymes play vital roles in scavenging ROS and alleviating oxidative damage under stress environment [33,34]. The activities of CAT and SOD in MeJA-treated root slices were significantly higher than those in the untreated root slices at 12, 24, and $48 \mathrm{~h}$ (Figure 3A,C). Although the activity of POD in MeJA-treated cassava root slices was significantly higher than that in untreated cassava root slices at $12 \mathrm{~h}$, there were no significant differences at other time points (Figure 3B). These results indicated that $10 \mathrm{mM}$ MeJA could alleviate cell oxidative damage through activating the activities of antioxidant enzymes, which might contribute to the burst of $\mathrm{H}_{2} \mathrm{O}_{2}$ and $\mathrm{O}_{2}{ }^{-}$ during storage time. 

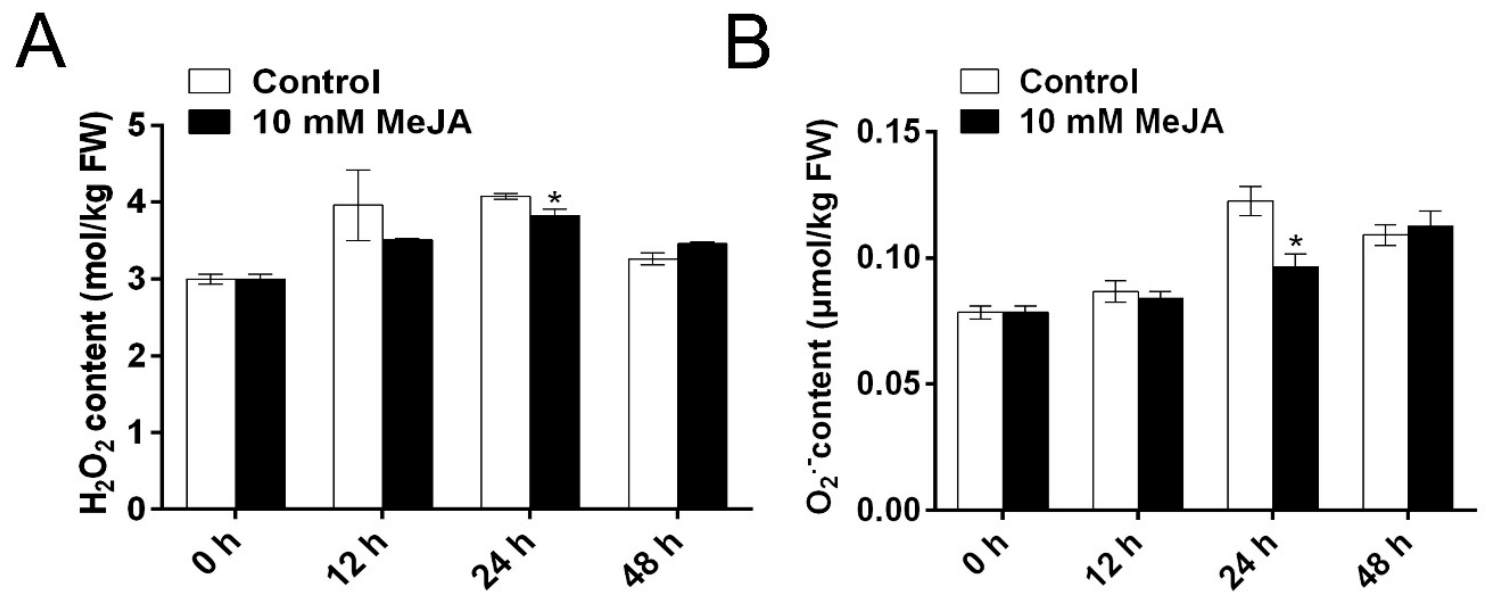

Figure 2. MeJA alleviates cell oxidative damage through modulation of reactive oxygen species (ROS) in cassava tuberous roots during PPD. The concentrations of $\mathrm{H}_{2} \mathrm{O}_{2}$ content (A) and $\mathrm{O}_{2}{ }^{-}$content (B) of cassava tuberous roots. Data are means \pm SD calculated from three biological replicate samples. Asterisk symbols $\left(^{*}\right)$ indicate significant differences according to Duncan's multiple range test at $p<0.05$ at the same time points. 

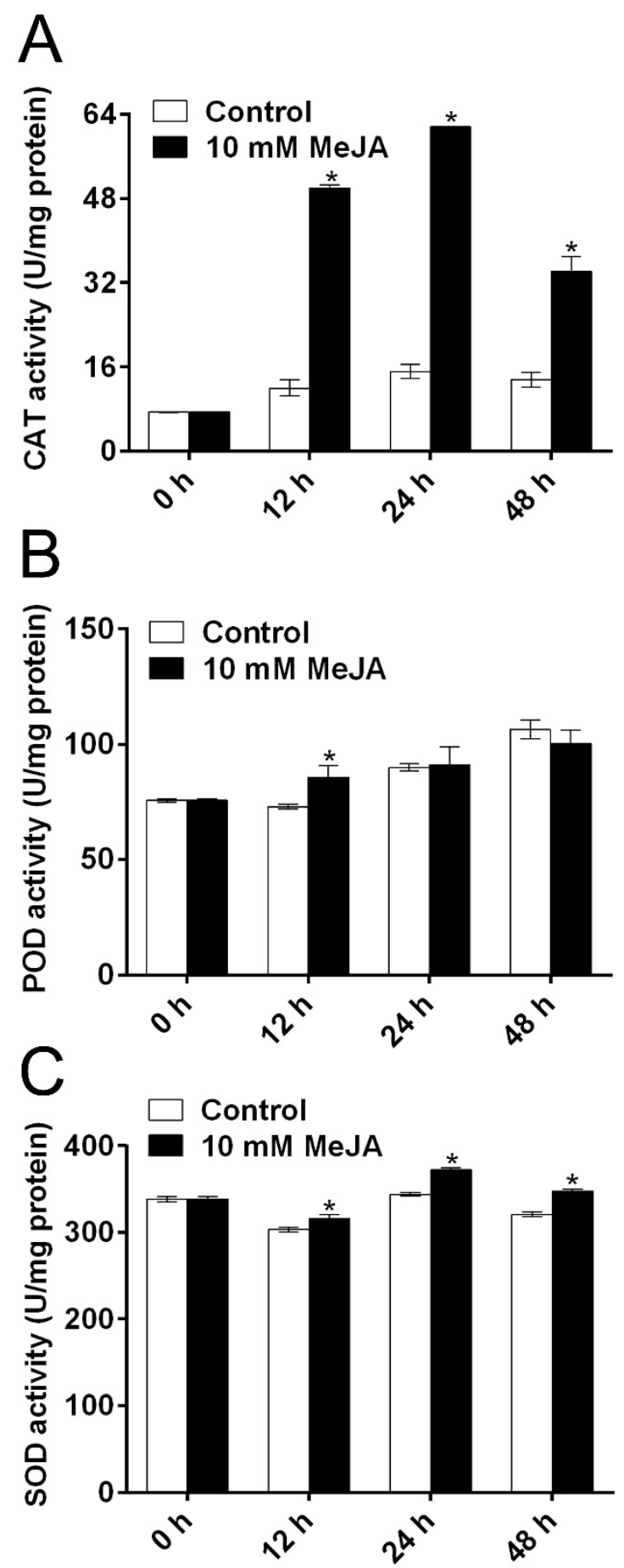

Figure 3. The modulation of MeJA treatment on antioxidant enzyme activities in cassava tuberous roots during PPD. Related activities of catalase (CAT) (A), peroxidase (POD) (B), and superoxide dismutase $(\mathrm{SOD})(\mathrm{C})$ in cassava tuberous roots. Data are means $\pm \mathrm{SD}$ calculated from at least four biological replicate samples. Asterisk symbols $\left(^{*}\right)$ indicate significant differences according to Duncan's multiple range test at $p<0.05$ at the same time.

\subsection{MeJA Positively Modulates the Quality of Cassava Root Slices}

During the process of PPD, starch concentration was significantly higher in MeJA-treated cassava root slices than that in the control root slices at 12 and $24 \mathrm{~h}$, while at $48 \mathrm{~h}$, a decrease was evident after MeJA treatment (Figure 4A). Soluble sugar concentration showed no significant difference between MeJA-treated cassava root slices and the control root slices (Figure 4B). Furthermore, MeJA treatment 
significantly increased ascorbic acid levels in comparison to the control during cassava slice storage (Figure 4C), and MeJA treatment significantly increased carotenoid concentration compared with the control, at 12 and $48 \mathrm{~h}$ (Figure 4D). These quality-related parameters showed that MeJA could reduce quality loss in cassava root slices during storage.
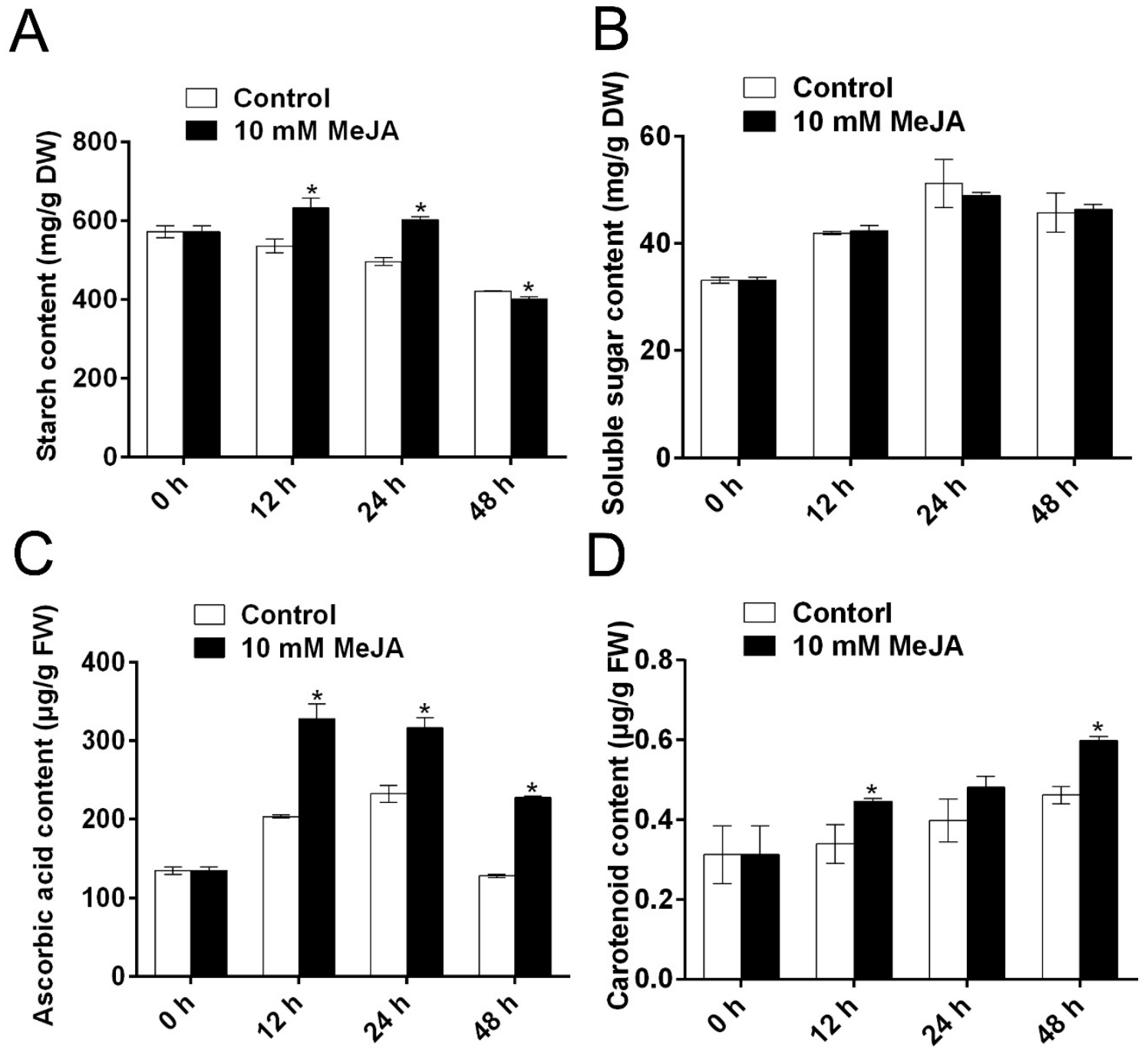

Figure 4. The modulation of MeJA treatment on the quality of cassava tuberous roots during PPD. The concentrations of starch content (A), soluble sugar content (B), ascorbic acid content (C), and carotenoid content (D) in cassava tuberous roots during PPD progression. Data are means \pm SD calculated from three biological replicate samples. Asterisk symbols $\left(^{*}\right)$ indicate significant differences according to Duncan's multiple range test at $p<0.05$ at the same time.

\subsection{MeJA Treatment Affects the Endogenous GA Content}

Interestingly, MeJA treatment increased endogenous GA concentration as compared to the control at 12 and $48 \mathrm{~h}$ during cassava storage (Figure 5A). Simultaneously, a high concentration of GA also significantly delayed the development of PPD (Figure 5B). These results demonstrated that MeJA-induced GA also had a significant effect on delaying PPD. 


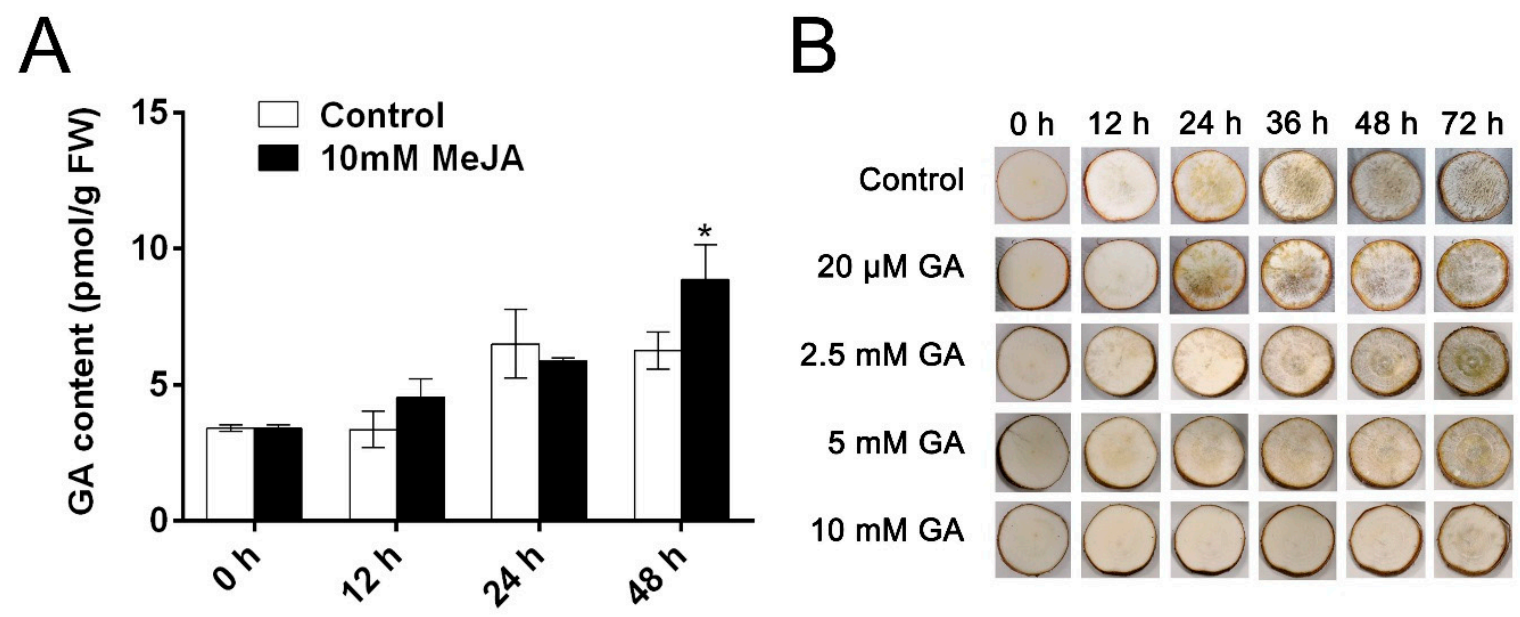

Figure 5. The effects of MeJA on the endogenous gibberellin (GA) levels in stored cassava slices. (A) The endogenous levels of GA in cassava storage root slices without and with MeJA pre-treatment. (B) Visual detection of storage root slices affected by GA pre-treatment. Data are means \pm SD calculated from three biological replicate samples. Asterisk symbols $\left({ }^{*}\right)$ indicate significant differences according to Duncan's multiple range test at $p<0.05$ at the same time.

\subsection{The Effect of MeJA on the Expression of Melatonin Biosynthesis Genes and Melatonin Level}

Besides GA, the endogenous melatonin level and the corresponding melatonin biosynthesis relative genes were also determined. Notably, all the genes except MeASMT1 were significantly upregulated after MeJA treatment in comparison to the control root slices at $12 \mathrm{~h}$ (Figure 6). Compared with the control samples, all these genes were significantly upregulated at $24 \mathrm{~h}$ after MeJA treatment (Figure 6). Meanwhile, the endogenous melatonin level also significantly increased after MeJA treatment at $24 \mathrm{~h}$ (Figure $6 \mathrm{H}$ ). Therefore, exogenous MeJA might act as a molecular regulator to activate melatonin biosynthesis, thereby delaying cassava PPD and alleviating cell oxidative damage. 
A

MeTDC1

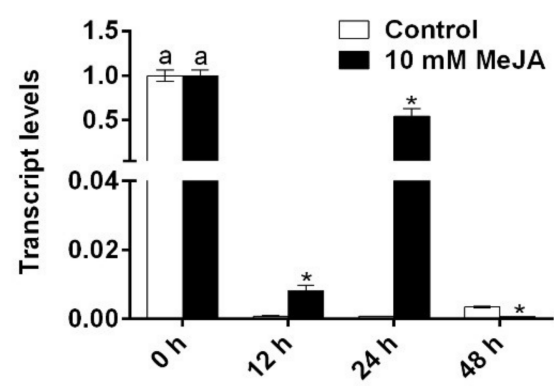

C

MeT5H

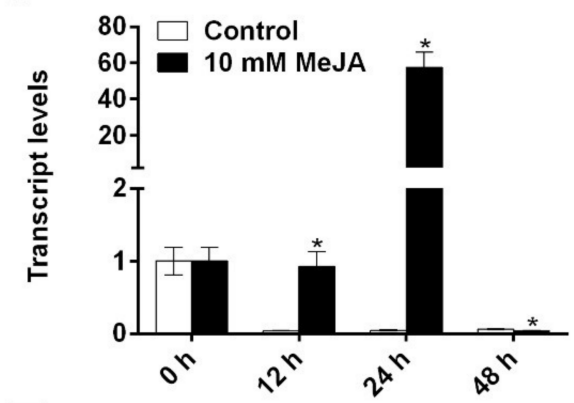

$E$

MeASMT1

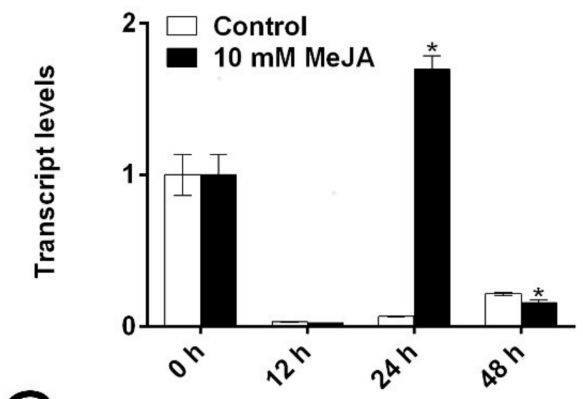

G MeASMT3

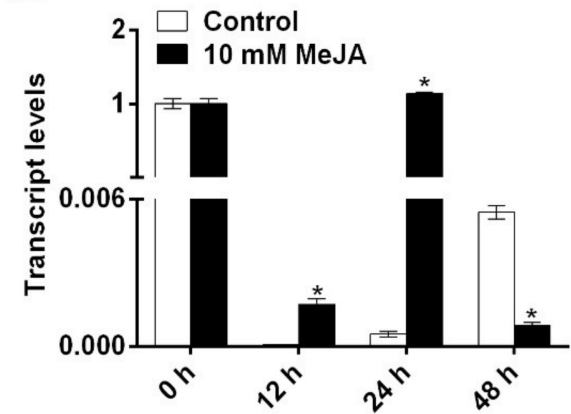

B

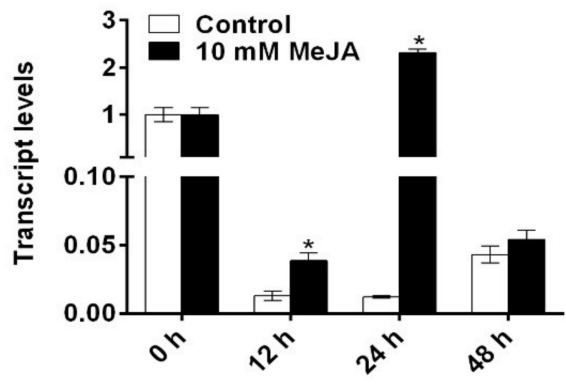

D

MeSNAT

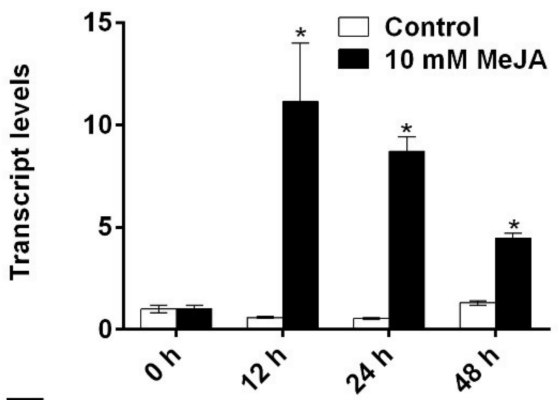

MEASMT2

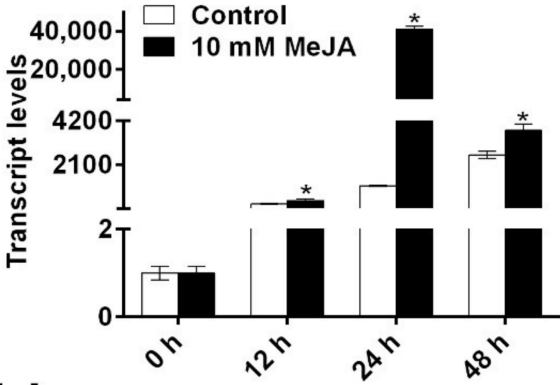

$\mathrm{H}$

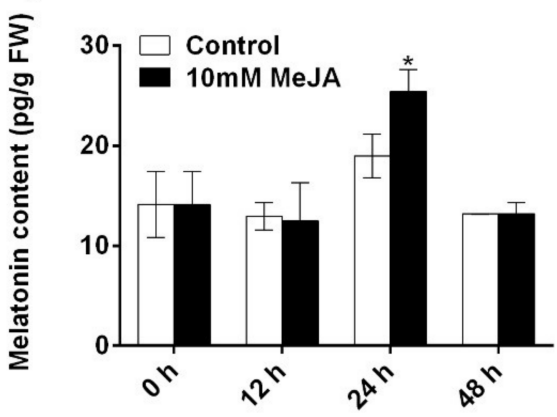

Figure 6. The effects of the MeJA on the expression levels of cassava melatonin biosynthesis genes and underlying endogenous melatonin. Expression levels of MeTDC1 (A), MeTDC2 (B), MeT5H (C), MeSNAT (D), MeASMT1 (E), MeASMT2 (F), and MeASMT3 (G) during PPD progression. The endogenous melatonin level in cassava storage root slices $(\mathbf{H})$. Data are means \pm SD calculated from three biological replicate samples. Asterisk symbols $\left({ }^{*}\right)$ indicate significant differences according to Duncan's multiple range test at $p<0.05$ at the same time.

\section{Discussion}

In this study, the activities of SOD, CAT, and POD in MeJA-treated cassava roots were significantly higher than those in the control roots (Figure 3). Consistently, the concentrations of $\mathrm{O}_{2}{ }^{-}$and $\mathrm{H}_{2} \mathrm{O}_{2}$ 
showed the opposite trend (Figure 2), thereby delaying PPD symptoms and alleviating cell oxidative damage. Previous studies have shown that the application of MeJA could increase the activities of SOD [17], POD [17,18], and CAT [17,18] in different fruits and plants, and thereby stress resistance [17]. SOD can eliminate $\mathrm{O}_{2}{ }^{-}$and transform it into $\mathrm{H}_{2} \mathrm{O}_{2}$, which is further reduced to $\mathrm{H}_{2} \mathrm{O}$ by CAT [35]. CAT, as a detoxifying system member, protects cells against the ROS accumulated within cells [19]. Overall, these results indicated that MeJA might delay PPD and decrease cell oxidative damage in cassava root slices through enhancing antioxidant enzyme activities and decreasing ROS accumulation.

After MeJA pre-treatment, the concentrations of ascorbic acid, carotenoid, and soluble sugar were increased, while the degradation of starch was reduced (Figure 4). Hu et al. [12] indicated that the application of $\mathrm{CaCl}_{2}$ could reduce the degradation of ascorbic acid and delay PPD, in accordance with this study. In addition, Chavez et al. [36] found that there is positive correlation between endogenous $\beta$-carotene level and cassava PPD tolerance, so the modulation of MeJA on carotenoids may contribute to its effect on cassava PPD. MeJA treatment is conducive to the maintenance of eggplant fruit quality during storage, through inhibiting the increase of calyx browning [18]. MeJA treatment can maintain higher concentrations of sugars and organic acids in fresh kiwifruit [20] and mangoes [21]. The degradation of starch can result in the increase of sugar [37,38]. Soluble sugar is the basis for the formation of fruit quality. Moreover, ascorbic acid also plays an essential role in plant antioxidant stress defense and nutrition [39]. Therefore, the effects of exogenous MeJA treatment on the above parameters might be used for delaying senescence as well as maintaining storage quality.

Plant growth regulators play important roles in many physiological processes and stress responses. This study showed that the endogenous GA level was higher in MeJA-treated cassava root slices than that in the control slices (Figure 5A). Furthermore, GA treatment has significant effects on delaying ripening and postponing senescence [40-42]. Besides GA, exogenous melatonin treatment delayed postharvest senescence in litchi [43], banana [44], peach [45], and strawberry [46]. In cassava, melatonin biosynthesis genes are transcriptionally upregulated by melatonin treatment [10], and the application of $\mathrm{CaCl}_{2}$ can also increase melatonin content through activating the expression of melatonin biosynthesis genes [12]. Herein, MeJA commonly activated the transcripts of MeTDC1/2, MeT5H, MeSNAT, and MeASMT1/2/3, so as to trigger endogenous melatonin levels in cassava root slices during cassava storage. Based on the relationship between plant growth regulators and fruit ripening as well as quality, we concluded that the modulation of MeJA on ROS might contribute to MeJA-mediated PPD and cassava quality. Figure 7 shows a possible model describing the potential relationships among MeJA, melatonin, ROS, GA, quality, and cassava PPD. PPD is connected with a ROS burst and the activation of underlying antioxidant enzymes. In this study, MeJA could alleviate cell oxidative damage through modulation of ROS and underlying antioxidant enzymes, and increase the concentration of melatonin and GA, resulting in a delayed deterioration rate. Therefore, the results indicated that MeJA could delay the cassava deterioration rate through the modulation of multiple physiological parameters (Figure 7). 


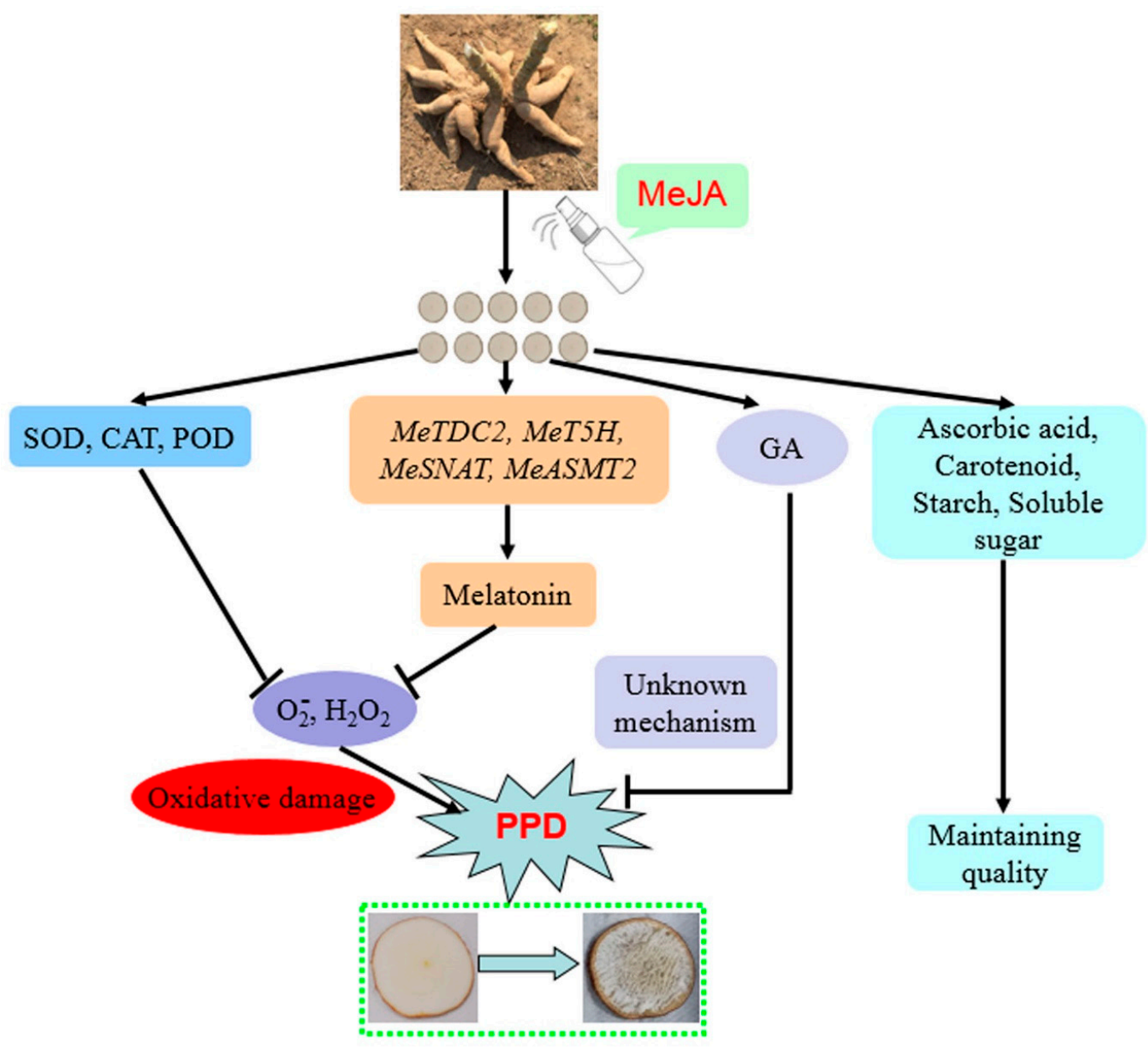

Figure 7. A possible model of MeJA-mediated cassava PPD.

\section{Conclusions}

MeJA delays the deterioration rate and alleviates cell oxidative damage through modulation of ROS accumulation and the underlying activities of SOD, CAT, and POD. In addition, exogenous MeJA has a significant effect on maintaining cassava quality, including ascorbic acid and carotenoids. Therefore, MeJA treatment is an effective and promising way to maintain a long postharvest life, decrease cell damage, and regulate storage quality in cassava.

Author Contributions: D.L. and Y.W. designed the experiments; G.L., B.L. and X.L. carried out the experiments and analyzed the data; G.L. wrote the manuscript, H.S. reviewed and edited the manuscript.

Funding: This research was supported by the Scientific Research Project of Higher Education in Hainan Education Department (No.Hnky2018-7) to Guoyin Liu, the startup funding and the scientific research foundation of Hainan University (No.kyqd1531) to Haitao Shi and the crop science postgraduate innovation project of Hainan university tropical agriculture and forestry college (No.ZWCX2018017) to Bing Li.

Conflicts of Interest: The authors declare no conflict of interest.

\section{References}

1. Morante, N.; Sánchez, T.; Ceballos, H.; Calle, F.; Pérez, J.C.; Egesi, C.; Cuambe, C.E.; Escobar, A.; Ortiz, D.; Chávez, A.L.; et al. Tolerance to postharvest physiological deterioration in cassava roots. Crop Sci. 2010, 50, 1333-1338. [CrossRef]

2. Iyer, S.; Mattinson, D.S.; Fellman, J.K. Study of the early events leading to cassavaroot postharvest deterioration. Trop. Plant Biol. 2010, 3, 151-165. [CrossRef] 
3. Buschmann, H.; Rodriguez, M.X.; Tohme, J.; Beeching, J.R. Accumulation of hydroxycoumarins during post-harvest deterioration of tuberous roots of cassava (Manihot esculenta crantz). Ann. Bot-London 2000, 86, 1153-1160. [CrossRef]

4. Salcedo, A.; Siritunga, D. Insights into the physiological, biochemical and molecular basis of postharvest deterioration in cassava (Manihot esculenta) roots. Am. J. Exp. Agric. 2011, 1, 414-431. [CrossRef]

5. Saravanan, R.; Ravi, V.; Stephen, R.; Thajudhin, S.; George, J. Post-harvest physiological deterioration of cassava (Manihot esculenta) - A review. Indian J. Agr. Sci. 2016, 86, 1383-1390.

6. Apel, K.; Hirt, H. Reactive oxygen species: Metabolism, oxidative stress, and signal transduction. Ann. Rev. Plant Biol. 2004, 55, 373-399. [CrossRef]

7. Hodges, D.M.; Lester, G.E.; Munro, K.D.; Toivonen, P.M.A. Oxidative stress: Importance for postharvest quality. HortScience 2004, 39, 924-929. [CrossRef]

8. Acedo, J.; Acedo, A. Controlling postharvest physiological deterioration and surface browning in cassava (Manihot esculenta Crantz) roots with hot water treatment. Acta Hortic. 2013, 989, 357-362. [CrossRef]

9. Sánchez, T.; Chávez, A.L.; Ceballos, H.; Rodriguez-Amaya, D.B.; Nestel, P.; Ishitani, M. Reduction or delay of post-harvest physiological deterioration in cassava roots with higher carotenoid content. J. Sci. Food Agr. 2006, 86, 634-639. [CrossRef]

10. Ma, Q.; Zhang, T.; Zhang, P.; Wang, Z. Melatonin attenuates postharvest physiological deterioration of cassava storage roots. J. Pineal Res. 2016, 60, 424-434. [CrossRef]

11. Hu, W.; Kong, H.; Guo, Y.; Zhang, Y.; Ding, Z.; Tie, W.; Yan, Y.; Huang, Q.; Peng, M.; Shi, H.; et al. Comparative physiological and transcriptomic analyses reveal the actions of melatonin in the delay of postharvest physiological deterioration of cassava. Front. Plant Sci. 2016, 7, e0136993. [CrossRef]

12. Hu, W.; Tie, W.; Ou, W.; Yan, Y.; Kong, H.; Zuo, J.; Ding, X.; Ding, Z.; Liu, Y.; Wu, C.; et al. Crosstalk between calcium and melatonin affects postharvest physiological deterioration and quality loss in cassava. Postharvest Biol. Tec. 2018, 140, 42-49. [CrossRef]

13. Cortés, D.F.; Reilly, K.; Okogbenin, E.; Beeching, J.R.; Iglesias, C.; Tohme, J. Mapping wound-response genes involved in post-harvest physiological deterioration (PPD) of cassava (Manihot esculenta Crantz). Euphytica 2002, 128, 47-53. [CrossRef]

14. Tumuhimbise, R.; Melis, R.; Shanahan, P. Genetic variation in cassava for postharvest physiological deterioration. Arch. Agron. Soil Sci. 2015, 61, 1333-1342. [CrossRef]

15. Fung, R.W.; Wang, C.Y.; Smith, D.L.; Gross, K.C.; Tao, Y.; Tian, M. Characterization of alternative oxidase (AOX) gene expression in response to methyl salicylate and methyl jasmonate pre-treatment and low temperature in tomatoes. J. Plant Physiol. 2006, 163, 1049-1060. [CrossRef]

16. Karaman, S.; Ozturk, B.; Genc, N.; Celik, S.M. Effect of preharvest application of methyl jasmonate on fruit quality of plum (Prunus salicina Lindell cv. "Fortune") at harvest and during cold storage. J. Food Proces. Pres. 2013, 37, 1049-1059. [CrossRef]

17. Wei, J.X.; Wen, X.C.; Tang, L. Effect of methyl jasmonic acid on peach fruit ripening progress. Sci. Hortic-Amsterdam 2017, 220, 206-213. [CrossRef]

18. Fan, L.L.; Shi, J.Y.; Zuo, J.H.; Gao, L.P.; Lv, J.Y.; Wang, Q. Methyl jasmonate delays postharvest ripening and senescence in the non-climacteric eggplant (Solanum melongena L.) fruit. Postharvest Biol. Tec. 2016, 120, $76-83$. [CrossRef]

19. Kim, Y.H.; Kim, Y.; Cho, E.; Kwak, S.; Kwon, S.; Bae, J.; Lee, B.; Meen, B.; Huh, G.H. Alterations in intracellular and extracellular activities of antioxidant enzymes during suspension culture of sweetpotato. Phytochemistry 2004, 65, 2471-2484. [CrossRef]

20. Wang, C.Y.; Buta, J.G. Maintaining quality of fresh-cut kiwifruit with volatile compounds. Postharvest Biol. Tec. 2003, 28, 181-186. [CrossRef]

21. González-Aguilar, G.A.; Fortiz, J.; Cruz, R.; Baez, R.; Wang, C.Y. Methyl jasmonate reduces chilling injury and maintains postharvest quality of mango fruit. J. Agr. Food Chem. 2000, 48, 515-519. [CrossRef]

22. Meng, D.M.; Song, T.Z.; Shen, L.; Zhang, X.H.; Sheng, J.P. Postharvest application of methyl jasmonate for improving quality retention of Agaricus bisporus fruit bodies. J. Agr. Food Chem. 2012, 60, 6056-6062. [CrossRef]

23. Wang, S.Y.; Bowman, L.; Ding, M. Methyl jasmonate enhances antioxidant activity and flavonoid content in blackberries Rubus sp. and promotes antiproliferation of human cancer cells. Food Chem. 2008, 107, 1261-1269. [CrossRef] 
24. Chanjirakul, K.; Wang, S.Y.; Wang, C.H.; Siriphanich, J. Effect of natural volatile compounds on antioxidant capacity and antioxidant enzymes in raspberries. Postharvest Biol. Tec. 2006, 40, 106-115. [CrossRef]

25. Kondo, S.; Mattheis, J. Aroma volatile biosynthesis in apples at harvest or after harvest affected by jasmonates. Acta Hort. 2006, 712, 381-388. [CrossRef]

26. Shafiq, M.; Singh, Z.; Khan, A.S. Time of methyl jasmonate application influences the development of 'Cripps Pink' apple fruit colour. J. Sci. Food Agr. 2013, 93, 611-618. [CrossRef]

27. Wang, S.Y.; Zheng, W. Preharvest application of methyl jasmonate increases fruit quality and antioxidant capacity in raspberries. Int. J. Food Sci. Tech. 2005, 40, 187-195. [CrossRef]

28. Kucuker, E.; Ozturk, B.; Celik, S.M.; Aksit, H. Pre-harvest spray application of methyl jasmonate plays an important role in fruit ripening, fruit quality and bioactive compounds of Japanese plums. Sci. Hortic-Amsterdam 2014, 176, 162-169. [CrossRef]

29. Wei, Y.; Chang, Y.; Zeng, H.; Liu, G.; He, C.; Shi, H. RAV transcription factors are essential for disease resistance against cassava bacterial blight via activation of melatonin biosynthesis genes. J. Pineal Res. 2018, 64, e12454. [CrossRef]

30. Wei, Y.; Hu, W.; Wang, Q.; Liu, W.; Wu, C.; Zeng, H.; Yan, Y.; Li, X.; He, C.; Shi, H. Comprehensive transcriptional and functional analyses of melatonin synthesis genes in cassava reveal their novel role in hypersensitive-like cell death. Sci. Rep. 2016, 6, 35029. [CrossRef]

31. Gao, J.F. Experimental Guidance Plant Physiology; Higher Education Press: Beijing, China, 2007; pp. $145-225$.

32. Cao, J.K.; Jiang, W.B.; Zhao, Y.M. Experiment Guidance of Postharvest Fruits and Vegetables Physiology and Biochemistry; Light Industry Press: Beijing, China, 2007.

33. Duan, J.J.; Li, J.; Guo, S.; Kang, Y. Exogenous spermidine affects polyamine metabolism in salinity-stressed Cucumis sativus roots and enhances short-term salinity. J. Plant Physiol. 2008, 165, 1620-1635. [CrossRef]

34. Rider, J.E.; Hacker, A.; Mackintosh, C.A.; Pegg, A.E.; Woster, P.M.; Casero, J. Spermine and spermidine mediate protection against oxidative damage caused by hydrogen peroxide. Amino Acids 2007, 33, 231-240. [CrossRef]

35. Anjum, S.A.; Wang, L.; Farooq, M.; Khan, I.; Xue, L. Methyl jasmonate-induced alteration in lipid peroxidation, antioxidative defence system and yield in soybean under drought. J. Agron. Crop Sci. 2011, 197, $296-301$. [CrossRef]

36. Chavez, A.L.; Bedoya, J.M.; Sánchez, T.; Iglesias, C.; Ceballos, H.; Roca, W. Iron, carotene, and ascorbic acid in cassava roots and leaves. Food Nutr. Bull. 2000, 21, 410-413. [CrossRef]

37. Fischer, C.; Holl, W. Food Reserves in Scots Pine (Pinus sylvestris L.). 1: Seasonal Changes in the Carbohydrate and Fat Reserves of Pine Needles. Trees 1991, 6, 147-155. [CrossRef]

38. Ketabchi, S.; Shahrtash, M. Effects of methyl jasmonate and cytokinin on biochemical responses of maize seedlings infected by Fusarium moniliforme. Asian J. Exp. Biol. Sci. 2011, 2, 299-305.

39. Mellidou, I.; Keulemans, J.; Davey, M.W.; Kanellis, A. Ascorbic acid accumulation, biosynthesis and recycling during tomato fruit ripening. Acta Hortic. 2012, 939, 255-261. [CrossRef]

40. Dagar, A.; Weksler, A.; Friedman, H.; Lurie, S. Gibberellic acid $\left(\mathrm{GA}_{3}\right)$ application at the end of pit ripening: Effect on ripening and storage of two harvests of 'september snow' peach. Sci. Hortic-Amsterdam 2012, 140, 125-130. [CrossRef]

41. Panigrahi, J.; Gheewala, B.; Patel, M.; Patel, N.; Gantait, S. Gibberellic acid coating: A novel approach to expand the shelf-life in green chilli (Capsicum annuum L.). Sci. Hortic-Amsterdam 2017, 225, 581-588. [CrossRef]

42. Huang, H.; Jing, G.X.; Wang, H.; Duan, X.W.; Qu, H.X.; Jiang, Y.M. The combined effects of phenylurea and gibberellins on quality maintenance and shelf life extension of banana fruit during storage. Sci. Hortic-Amsterdam 2014, 167, 36-42. [CrossRef]

43. Zhang, Y.; Huber, D.; Hu, M.; Jiang, G.; Gao, Z.; Xu, X.; Jiang, Y.; Zhang, Z. Melatonin delay of postharvest browning in litchi fruit by enhancing anti-oxidative processes and oxidation repair. J. Agr. Food Chem. 2018. [CrossRef]

44. Hu, W.; Yang, H.; Tie, W.; Yan, Y.; Ding, Z.; Liu, Y.; Wu, C.; Wang, J.; Reiter, R.; Tan, D.; et al. Natural variation in banana varieties highlights the role of melatonin in postharvest ripening and quality. J. Agr. Food Chem. 2017, 65, 9987-9994. [CrossRef] 
45. Gao, H.; Zhang, Z.; Chai, H.; Cheng, N.; Yang, Y.; Wang, D.; Yang, T.; Cao, W. Melatonin treatment delays postharvest senescence and regulates reactive oxygen species metabolism in peach fruit. Postharvest Biol. Tec. 2016, 118, 103-110. [CrossRef]

46. Aghdam, M.S.; Fard, J.R. Melatonin treatment attenuates postharvest decay and maintains nutritional quality of strawberry fruits (Fragaria $\times$ anannasa cv. Selva) by enhancing GABA shunt activity. Food Chem. 2017, 221, 1650-1657. [CrossRef]

(C) 2019 by the authors. Licensee MDPI, Basel, Switzerland. This article is an open access article distributed under the terms and conditions of the Creative Commons Attribution (CC BY) license (http://creativecommons.org/licenses/by/4.0/). 